\title{
Atmospheric Trace Molecule Spectroscopy (ATMOS) Experiment Version 3 data retrievals
}

\author{
Fredrick W. Irion, Michael R. Gunson, Geoff C. Toon, Albert Y. Chang, \\ Annmarie Eldering, Emmanuel Mahieu, Gloria L. Manney, Hope A. Michelsen, \\ Elizabeth J. Moyer, Michael J. Newchurch, Gregory B. Osterman, Curtis P. Rinsland, \\ Ross J. Salawitch, Bhaswar Sen, Yuk L. Yung, and Rodolphe Zander
}

\begin{abstract}
Version 3 of the Atmospheric Trace Molecule Spectroscopy (ATMOS) experiment data set for some 30 trace and minor gas profiles is available. From the IR solar-absorption spectra measured during four Space Shuttle missions (in 1985, 1992, 1993, and 1994), profiles from more than 350 occultations were retrieved from the upper troposphere to the lower mesosphere. Previous results were unreliable for tropospheric retrievals, but with a new global-fitting algorithm profiles are reliably returned down to altitudes as low as $6.5 \mathrm{~km}$ (clouds permitting) and include notably improved retrievals of $\mathrm{H}_{2} \mathrm{O}$, $\mathrm{CO}$, and other species. Results for stratospheric water are more consistent across the ATMOS spectral filters and do not indicate a net consumption of $\mathrm{H}_{2}$ in the upper stratosphere. A new sulfuric-acid aerosol product is described. An overview of ATMOS Version 3 processing is presented with a discussion of estimated uncertainties. Differences between these Version 3 and previously reported Version 2 ATMOS results are discussed. Retrievals are available at http://atmos.jpl.nasa.gov/atmos. (c) 2002 Optical Society of America

OCIS codes: $\quad 010.1280,300.1030,280.0280$.
\end{abstract}

\section{Introduction}

The ATMOS experiment was designed to measure the solar-absorption spectra of Earth's atmosphere from space and determine profile of the vertical volume mixing ratio (VMR) of trace and minor species

F. W. Irion (bill.irion@jpl.nasa.gov), M. R. Gunson, G. C. Toon, A. Y. Chang, A. Eldering, G. L. Manney, G. B. Osterman, R. J. Salawitch, and B. Sen are with the Jet Propulsion Laboratory, California Institute of Technology, Pasadena, California 91109. A. Eldering is also at the University of California, Los Angeles, California 90095. E. Mahieu at the University of Liège, 4000 Liège, Belgium. G. L. Manney is visiting at New Mexico Highlands University, Las Vegas, New Mexico 87701. H. A. Michelson is at Sandia National Laboratories, Livermore, California 94551. E. J. Moyer and Y. L. Yung are at this California Institute of Technology, Pasadena, California 91125. E. J. Moyer is now at Harvard University, Cambridge, Massachutesetts 02138. M. J. Newchurch is at the University of Alabama at Huntsville, Huntsville, Alabama 35899 and the National Center for Atmospheric Research Boulder, Colorado 80305. C. P. Rinsland is at NASA Langley Research Center, Langley, Virginia 23681.

Received 4 December 2001; revised manuscript received $27 \mathrm{Au}$ gust 2002

0003-6935/02/06968- $12 \$ 15.00 / 0$

(C) 2002 Optical Society of America spectroscopically active in the IR. The instrument is a Fourier-transform interferometer that measures solar absorption at a spectral resolution of $\approx 0.01$ $\mathrm{cm}^{-1}$ (48-cm optical path difference). Its spectral response is $600-4800 \mathrm{~cm}^{-1}$ over several bandpass filters. Atmospheric Trace Molecule Spectroscopy (ATMOS) has returned data from inside and outside the Arctic and Antarctic vortices, from midlatitudes, and from subtropics over four Space Shuttle flights: Spacelab 3 and the Atmospheric Laboratory for Applications and Science (ATLAS)-1, -2, and -3 missions. In Fig. 1 we illustrate the observation geometry during a sunset occultation, and in Fig. 2 we illustrate the geographical distribution of ATMOS retrievals for the four flights. In Table 1 and Fig. 3 we summarize observations within each spectral filter. Details about the instrument are in Ref. 1, and its deployment on the Shuttle is described in Ref. 2.

ATMOS Version 2 retrievals used an onion-peeling algorithm. ${ }^{3-5}$ This approach was successful for stratospheric measurements (see Ref. 2 and references therein). However, for ATLAS-1 and -2 missions the instrument suntracker (using visible wavelengths) often lost lock on the Sun as the ray passed through the optically thick lowerstratospheric aerosol layer created by the eruption of 


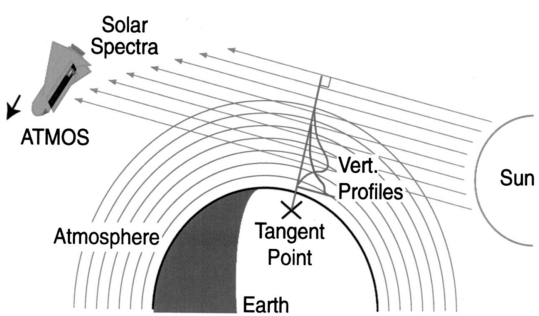

Fig. 1. Schematic of viewing geometry. A sunset occultation is illustrated as the Shuttle enters Earth's shadow. With selectable instrument fields of view of $1,1.4$, and $2.8 \mathrm{mrad}$, an observation field of view of 2,3 , or $6 \mathrm{~km}$ is achieved at the tangent altitude (defined at the central ray), typically $\sim 2000 \mathrm{~km}$ from the Shuttle. The sampling time of $2.2 \mathrm{~s}$ allows a vertical spacing between spectra of $\sim 4 \mathrm{~km}$ in the upper atmosphere, decreasing through the lower stratosphere and upper troposphere to $\sim 1 \mathrm{~km}$ due to refraction and drift of the suntracker up the solar disk.

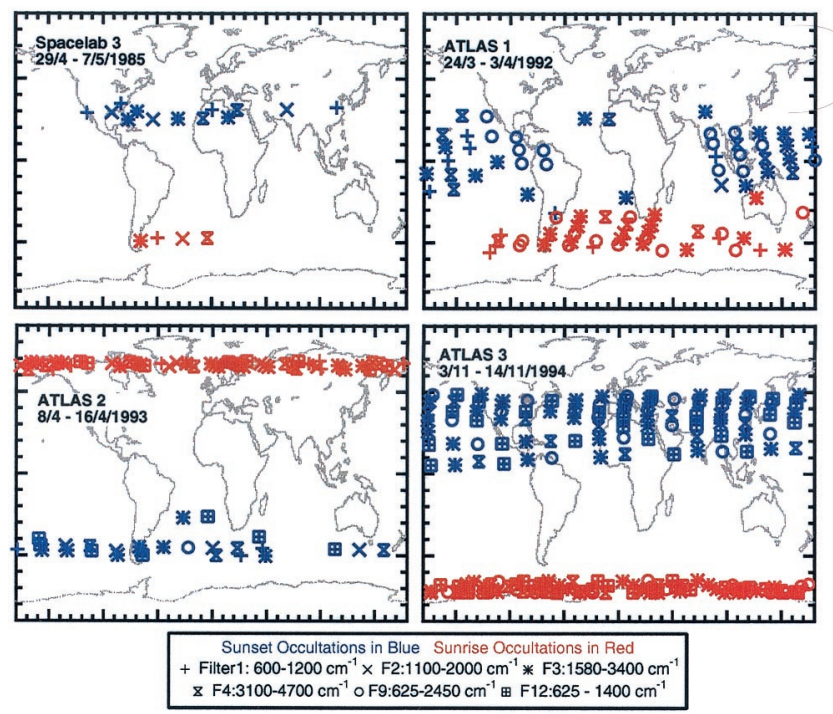

Fig. 2. Distribution of ATMOS sunset (blue) and sunrise (red) occultations from four Space Shuttle missions. The different symbols correspond to different spectral filters, as noted.
Mt. Pinatubo in 1991. Significantly lower aerosol loading during the ATLAS-3 mission in 1994 allowed good-quality spectra at tropospheric tangent altitudes, but Version 2 profile retrievals were often unrealistic at tangent heights in the upper troposphere (Fig. 4). Additionally, Version 2 software was designed to fit the absorption of only one gas at a time; generally, absorptions of nontarget gases were calculated $a$ priori from an assumed vertical VMR profile and remained fixed while the target gas was fitted. This rarely presented a problem in the stratosphere where the spectral lines of different gases tend to be well resolved, and only occasionally would it be necessary to fit sequentially (and iterate on) two or more gases in one spectral window. However, at lower tangent heights the stronger tropospheric absorption by minor gases, such as $\mathrm{H}_{2} \mathrm{O}, \mathrm{CO}_{2}, \mathrm{~N}_{2} \mathrm{O}$, and $\mathrm{CH}_{4}$, as well as increased pressure broadening, often caused spectral lines of interest to overlap on the wings. A sequential and iterative-fitting procedure for tropospheric retrievals would have been too timeconsuming to use routinely. Instead for Version 3, a robust method of simultaneously fitting multiple gases within a window is employed. This is combined with a global-fit algorithm to retrieve a vertical VMR profile simultaneously at all altitudes within an occultation. This procedure is much more efficient at tropospheric tangent heights. The ATMOS Version 3 tropospheric retrievals of gases such as $\mathrm{CO}$, $\mathrm{C}_{2} \mathrm{H}_{2}, \mathrm{C}_{2} \mathrm{H}_{6}, \mathrm{OCS}, \mathrm{HCN}$, and $\mathrm{H}_{2} \mathrm{O}$ are significantly improved over Version 2, and retrievals of gases such as $\mathrm{O}_{3}, \mathrm{NO}, \mathrm{NO}_{2}$, and $\mathrm{HNO}_{4}$ have been extended to lower altitudes.

\section{Algorithm Description}

The ATMOS Version 3 processing scheme is adapted from that of the Jet Propulsion Laboratory MkIV Fourier-transform IR interferometer program (the GGG code in Ref. 6). The MkIV instrument, ${ }^{7}$ similar to the ATMOS spectrometer, retrieves vertical gas profiles from solar-absorption spectra from balloon

Table 1. Number of Occultations Analyzed for ATMOS Version 3 Retrievals

\begin{tabular}{|c|c|c|c|c|c|}
\hline \multirow{2}{*}{$\begin{array}{c}\text { Filter and } \\
\text { Bandwidth }\left(\mathrm{cm}^{-1}\right)\end{array}$} & \multirow{2}{*}{$\begin{array}{l}\text { Average Signal to Noise } \\
\qquad(1 \sigma \text { std. dev. })\end{array}$} & \multicolumn{4}{|c|}{ Number of Occultations } \\
\hline & & Spacelab 3 & ATLAS-1 & ATLAS-2 & ATLAS-3 \\
\hline \multirow[t]{2}{*}{ Filter $1600-1200$} & \multirow[t]{2}{*}{$242 \pm 48$} & $1 \mathrm{SR}^{a}$ & $7 \mathrm{SR}$ & $11 \mathrm{SR}$ & \multirow[t]{2}{*}{ - } \\
\hline & & $3 \mathrm{SS}^{b}$ & $7 \mathrm{SS}$ & $4 \mathrm{SS}$ & \\
\hline \multirow[t]{2}{*}{ Filter 2 1100-2000 } & \multirow[t]{2}{*}{$167 \pm 39$} & $1 \mathrm{SR}$ & $1 \mathrm{SR}$ & $8 \mathrm{SR}$ & \multirow[t]{2}{*}{ - } \\
\hline & & $3 \mathrm{SS}$ & $1 \mathrm{SS}$ & $7 \mathrm{SS}$ & \\
\hline \multirow[t]{2}{*}{ Filter 3 1580-3400 } & \multirow[t]{2}{*}{$74 \pm 11$} & $1 \mathrm{SR}$ & $15 \mathrm{SR}$ & $20 \mathrm{SR}$ & $29 \mathrm{SR}$ \\
\hline & & $3 \mathrm{SS}$ & $11 \mathrm{SS}$ & $9 \mathrm{SS}$ & $34 \mathrm{SS}$ \\
\hline \multirow[t]{2}{*}{ Filter 4 3100-4700 } & \multirow[t]{2}{*}{$98 \pm 35$} & $1 \mathrm{SR}$ & $8 \mathrm{SR}$ & $10 \mathrm{SR}$ & $13 \mathrm{SR}$ \\
\hline & & $2 \mathrm{SS}$ & $4 \mathrm{SS}$ & $5 \mathrm{SS}$ & $15 \mathrm{SS}$ \\
\hline \multirow[t]{2}{*}{ Filter 9 600-2450 } & \multirow[t]{2}{*}{$122 \pm 40$} & \multirow[t]{2}{*}{-} & $15 \mathrm{SR}$ & \multirow[t]{2}{*}{$1 \mathrm{SS}$} & $14 \mathrm{SR}$ \\
\hline & & & $14 \mathrm{SS}$ & & $17 \mathrm{SS}$ \\
\hline \multirow[t]{2}{*}{ Filter $12600-1400$} & \multirow[t]{3}{*}{$255 \pm 36$} & \multirow[t]{2}{*}{-} & \multirow[t]{2}{*}{-} & $11 \mathrm{SR}$ & $27 \mathrm{SR}$ \\
\hline & & & & $7 \mathrm{SS}$ & $30 \mathrm{SS}$ \\
\hline Total & & 15 & 83 & 93 & 179 \\
\hline
\end{tabular}

\footnotetext{
${ }^{a}$ Sunrise.
}

${ }^{b}$ Sunset. 


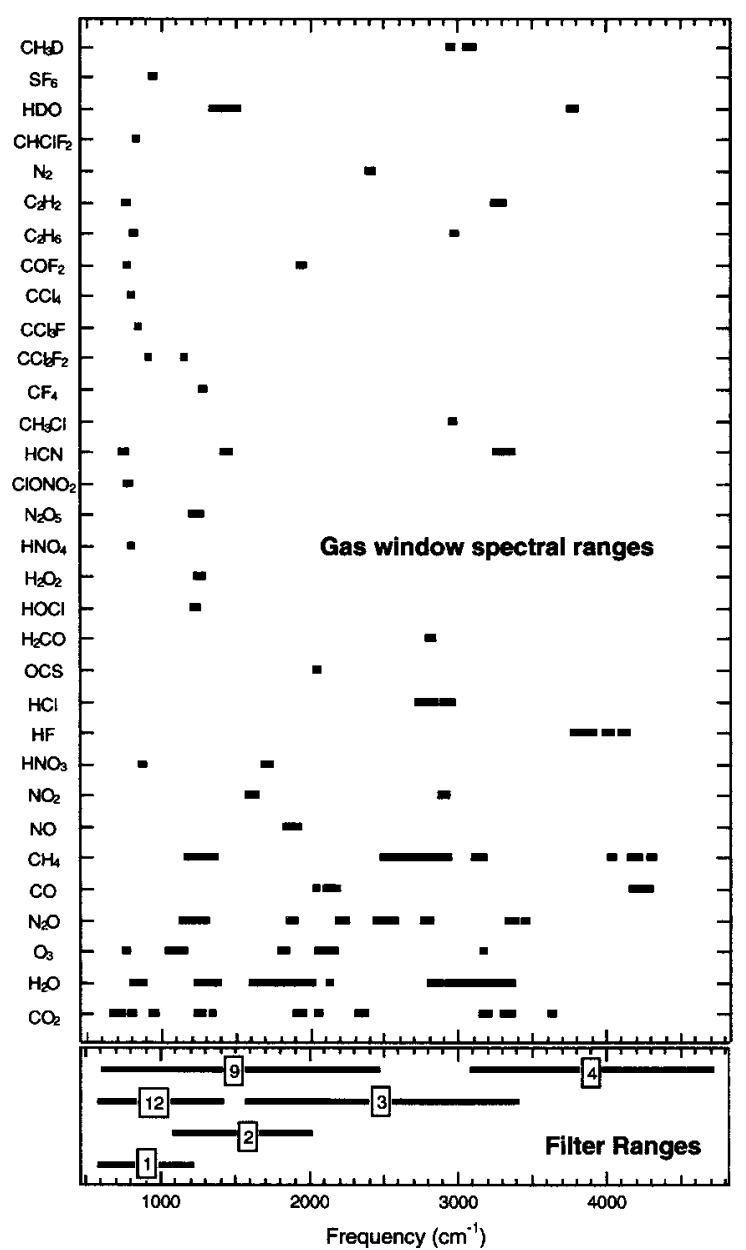

Fig. 3. ATMOS Version 3 spectral ranges for gas retrievals (upper panel) and ranges for spectral filters (lower panel). The numbers in the lower panel refer to the filter number.

platforms and total column measurements from the ground. For ATMOS the retrieval software was configured for space-based observation. Simplified illustrations of the global-fit retrieval procedure are shown in Figs. 5-7. Details of the forward modeling and inversion procedure are in Ref. 8. However, here, we discuss features of the software that are specific to ATMOS.

The spectra used in Version 3 are the same as those used in Version 2. The telluric limb spectra were ratioed against an averaged, near-simultaneous exoatmospheric spectrum (determined at altitudes greater than $165 \mathrm{~km}$ and free of telluric absorptions). This procedure removed solar and instrumental features, such as the spectral responses of the detector and filters, and lines of residual $\mathrm{H}_{2} \mathrm{O}$ and $\mathrm{CO}_{2}$ in the housing. Self-calibrated limb-transmittance spectra (i.e., on a scale of zero to unity) were produced, greatly simplifying later calculations (see, for example, Fig. 1 in Ref. 9).

\section{A. Model Atmosphere}

For Version 3 the atmosphere is modeled as homogeneous $1-\mathrm{km}$-thick layers centered from 0.5 to $99.5 \mathrm{~km}$

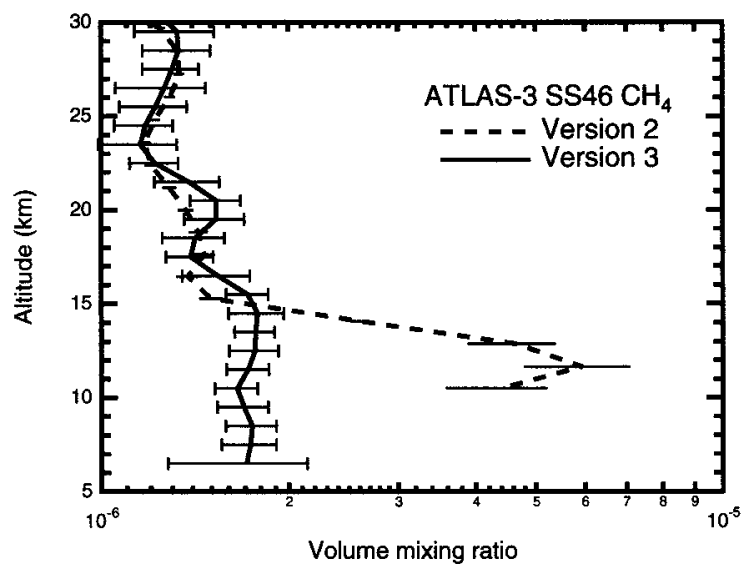

Fig. 4. Sample comparison of a single occultation methane profile from the software of ATMOS Versions 2 and 3 retrieval. Error bars are random errors. Version 3 random errors are calculated differently from Version 2 and tend to be the same or greater than Version 2 (see text). The Version 2 retrieval clearly produces an unrealistic profile in the free troposphere.

in altitude. Between these layers, temperature and gas VMRs are assumed to vary linearly with altitude. Preliminary determinations of atmospheric temperature-pressure profiles with Version 3 software and temperature-sensitive $\mathrm{CO}_{2}$ lines, similar to the analyses in Ref. 10, did not produce temperaturepressure profiles statistically different from those of Version 2. The same pressure-temperature profiles retrieved for Version 2 were therefore used in Version 3. Between 12 and $18 \mathrm{~km}$, temperatures retrieved from ATMOS spectra were merged with National

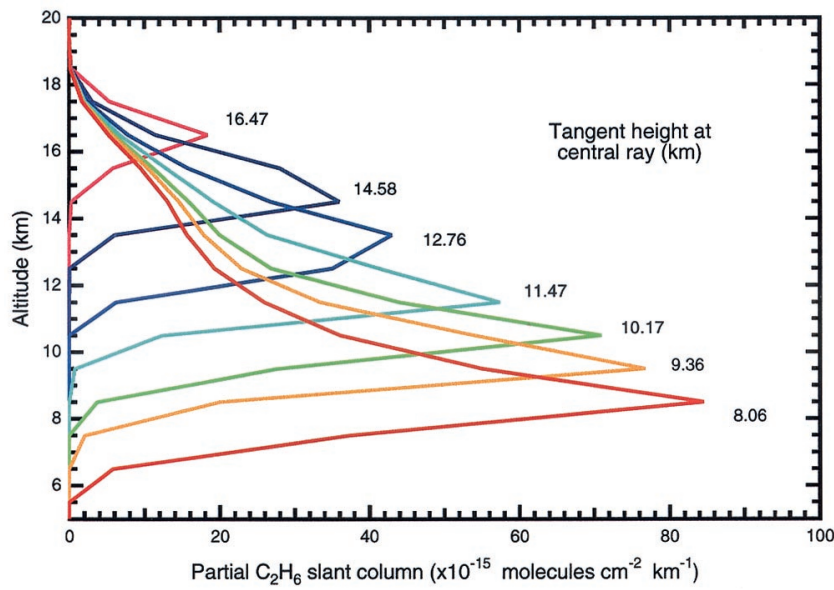

Fig. 5. Sample calculation of partial slant columns as a function of altitude. $\mathrm{C}_{2} \mathrm{H}_{6}$ is used as an example. Assumed mixing ratio profiles are used to calculate the slant path and slant columns from the instrument to the Sun through the model atmosphere for each spectrum. This is done for both target and nontarget gases. Note that an observation's field of view can encompass more than one model layer near the tangent point. (The vertical resolution is worse than the model layer spacing.) Thus contributions to the total slant column can be made from one or two layers immediately below the tangent point in addition to the contributions from all the layers above. 

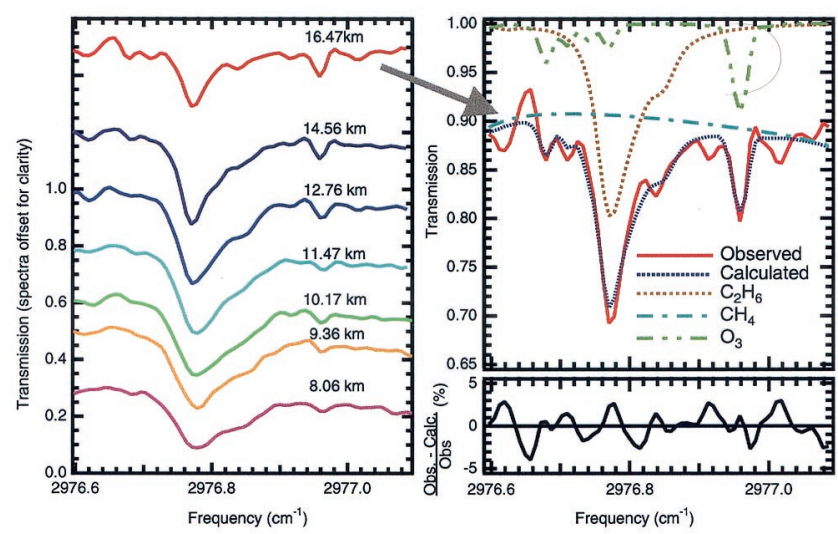

Fig. 6. Left, successive measured absorption spectra in a $\mathrm{C}_{2} \mathrm{H}_{6}$ microwindow and right, a fitted spectrum and residual. The slant paths are used to calculate absorptions for target and nontarget gases, and the slant columns (Fig. 4) are scaled until the best fit with observation is achieved. Where more than one microwindow is used for analysis, the retrieved slant columns are averaged.

Centers for Environmental Prediction (NCEP) profiles interpolated to the tangent-point locations with NCEP temperatures used at altitudes below $12 \mathrm{~km}$. Temperature errors are estimated to be $2 \mathrm{~K}$ between 18 and $70 \mathrm{~km}$ for filters 1 and 12 and $4 \mathrm{~K}$ below $18 \mathrm{~km}$. For other filters, temperature error is estimated to be $4 \mathrm{~K}$ at all altitudes below $70 \mathrm{~km}$.

\section{B. Zenith Angle/Tangent Pressure Determination}

The Version 3 algorithm requires the zenith-pointing angle of the instrument to ray trace from the instrument to the Sun and determine the tangent height and pressure of a spectrum. The zenith angle is determined by iterative adjustment to match a retrieved and an a priori $\mathrm{CO}_{2}$ slant column (the integrated amount of $\mathrm{CO}_{2}$ in the line of sight). This $a$ priori $\mathrm{CO}_{2}$ slant column is determined with an assumed VMR profile. Assumed $\mathrm{CO}_{2}$ profiles used for ATLAS-1, -2, and -3 retrievals were the same as for Version 2 (Fig. 8). However, the Spacelab 3 profile was increased uniformly by 6 ppm below a $90-\mathrm{km}$
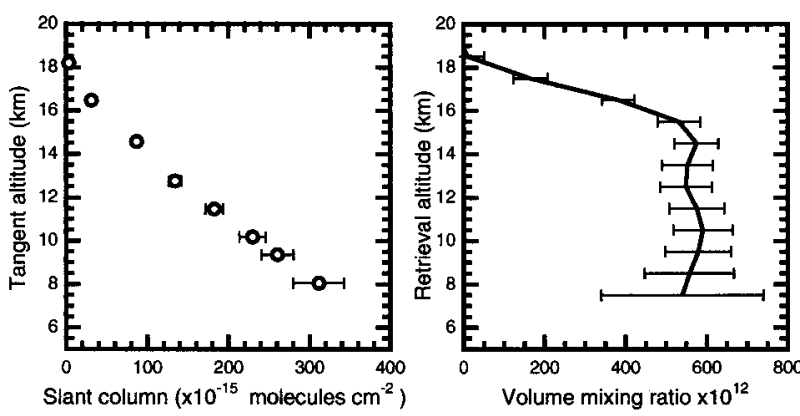

Fig. 7. When the partial slant column matrix (Fig. 4) is used, left, the averaged slant columns are inverted to, right, the retrieved vertical mixing ratio profile. The procedure (beginning with the description in Fig. 4) is then iterated until convergence is achieved. (Note that the retrieved altitude grid is not the same as that for the tangent altitudes. Error bars reflect only signal to noise and fitting error.)

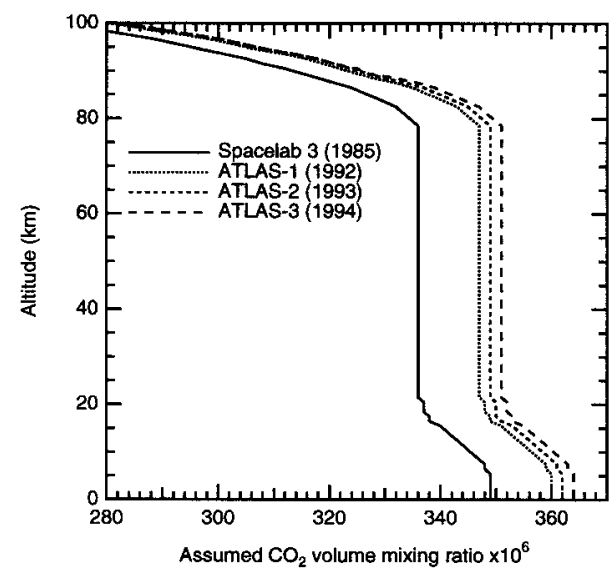

Fig. 8. Assumed $\mathrm{CO}_{2}$ VMR profiles for ATMOS zenith-angle determination.

altitude for better agreement with National Oceanic and Atmospheric Administration (NOAA) Climate Monitoring and Diagnostics Laboratory $\mathrm{CO}_{2}$ flask analyses. These pressure retrievals were made to a maximum altitude of $100 \mathrm{~km}$. No provision was made for the effects of non local thermodynamic equilibrium (LTE). However, note that a previous study of ATMOS Spacelab 3 results found that $\mathrm{CO}_{2}\left(v_{2}\right)$ vibrational temperatures were very close to LTE up to $100 \mathrm{~km}$ for solar-absorption measurements. ${ }^{11}$

\section{Selection of Microwindows}

As noted above, previous versions of the ATMOS retrieval software could fit the absorption of only one target gas at a time. The ability of Version 3 retrieval software to fit simultaneously absorptions of several gases allows a more flexible selection of spectral microwindows for retrieval of several gases with more reliable tropospheric results. Wherever possible the spectral lines and altitude ranges of target gases were chosen to keep absorption depths between $10 \%$ and $50 \%$ (for a good signal in the former case and to avoid saturation in the latter). Lines with ground-state energies below $400 \mathrm{~cm}^{-1}$ were selected to reduce errors from temperature uncertainty. It was not always possible to use such unsaturated, temperature-insensitive lines, particularly at low altitudes where much of the spectra could be blacked out. In this case, weaker high-J lines in a $\mathrm{P}$ or $\mathrm{R}$ branch with a concomitant increase in temperature sensitivity were used. Spectral ranges used in Version 3 retrievals are illustrated in Fig. 3, and a full listing of microwindows is available at the ATMOS web site, http://atmos.jpl.nasa.gov/atmos.

\section{Spectral Line Lists}

The spectral line lists used for Version 3 retrievals are the same as those used by MkIV retrievals and largely correspond to the ATMOS main and supplemental line lists. ${ }^{12}$ Differences between the line lists, and their effect on retrievals, are described below. 
1. $\mathrm{CCl}_{2} \mathrm{~F}_{2}, \mathrm{CCl}_{3} \mathrm{~F}, \mathrm{CHCIF}_{2}, \mathrm{HNO}_{4}, \mathrm{~N}_{2} \mathrm{O}_{5}, \mathrm{CCl}_{4}$, $\mathrm{CF}_{4}$ and $\mathrm{SF}_{6}$

For Version 2 retrievals, measured cross sections were used for the forward model calculations for the broad or unresolved spectral features of these molecules. ${ }^{12}$ For the MkIV/ATMOS Version 3 line list, pseudo-lines derived from these cross-section data were utilized, such lines preserving the individual band strengths. Comparison between retrievals of stratospheric ATMOS Version 2 and Version 3 indicated no significant systematic biases introduced by using such pseudo-lines.

\section{2. $\mathrm{HNO}_{3}$}

As described in Ref. 12, Version 2 analyses of ATMOS spectral data encompassing both the $\nu_{2}$ and $\nu_{5}$ bands indicated a systematic bias in retrieved profiles between the bands. For consistency across ATMOS spectral filters the strengths of $v_{2}$ band lines were therefore scaled by 1.1 for Version 2 results, which were within the estimated error of the line strengths. However, a later review of $\mathrm{HNO}_{3}$ spectroscopy results indicated that, among different researchers, band strengths reported were more consistent for the $v_{2}$ band than for the $\nu_{5}$ band. ${ }^{13}$ Thus for Version 3 results we elected to use the HITRAN 1996 line compilation, ${ }^{14}$ with the $v_{2}$ band strengths unchanged, but the strengths of the $v_{5}$ lines scaled by 0.9. ATMOS Version $3 \mathrm{HNO}_{3}$ retrievals are therefore higher than those of Version 2 by $\sim 10 \%$.

\section{3. $\mathrm{CH}_{3} \mathrm{D}$}

The line parameters provided in Ref. 15 were employed. This allowed a larger number of $\mathrm{CH}_{3} \mathrm{D}$ lines to be used in Version 3 analyses; however, the profile results were comparable with those of Version 2.

\section{E. Diurnal Corrections for $\mathrm{NO}$ and $\mathrm{NO}_{2}$}

The stratospheric concentrations of $\mathrm{NO}$ and $\mathrm{NO}_{2}$ are photochemically sensitive and can vary along the line of sight, significantly so with the changing solar zenith angle across the terminator. Below $25 \mathrm{~km}$, vertical VMR profiles uncorrected for this effect can be in error by $20 \%$ for $\mathrm{NO}_{2}$ and more than $100 \%$ for NO. ${ }^{16}$ Diurnal corrections for ATMOS Version $2 \mathrm{NO}$ and $\mathrm{NO}_{2}$ are discussed in Ref. 16, and for Version 3 we use a similar procedure described in Ref. 17. Diurnally corrected and uncorrected $\mathrm{NO}$ and $\mathrm{NO}_{2}$ retrievals are given at the ATMOS web site.

\section{Error Budget}

The precision and accuracy of retrieved mixing ratio profiles can vary widely depending on species, spectral filter, and altitude. The signal-to-noise error calculation for mixing ratio retrievals uses a different scheme than that of Version 2.5 Errors have therefore been reevaluated for Version 3. Despite the wider spectral windows and improved fitting, a more conservative scheme for error estimation tends to make the Version 3 random errors the same as or higher than those of Version 2.

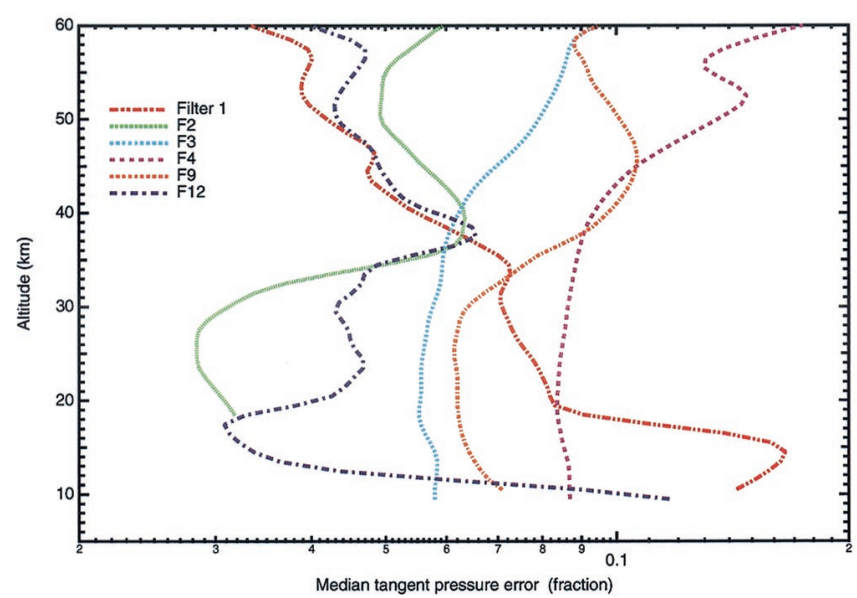

Fig. 9. Median fractional random error in tangent pressure for an individual occultation.

\section{A. Random Error}

Random errors for retrievals include a finite signal to noise, uncertainty in the tangent pressure, uncertainty in the temperature profiles, and zero baseline offset. An estimated tangent pressure error by a filter is illustrated in Fig. 9, while a total random error for selected gases and filters is shown in Figs. 10 and 11. Complete data for all gases and filters are available at the ATMOS web site (http://atmos.jpl.nasa.gov/atmos/).

\section{Finite Signal to Noise}

The signal-to-noise ratio (SNR) of a particular spectrum is estimated from the root mean square of the fluctuations in a nonabsorbing region. For individual spectra, SNRs determined by Version 2 process-

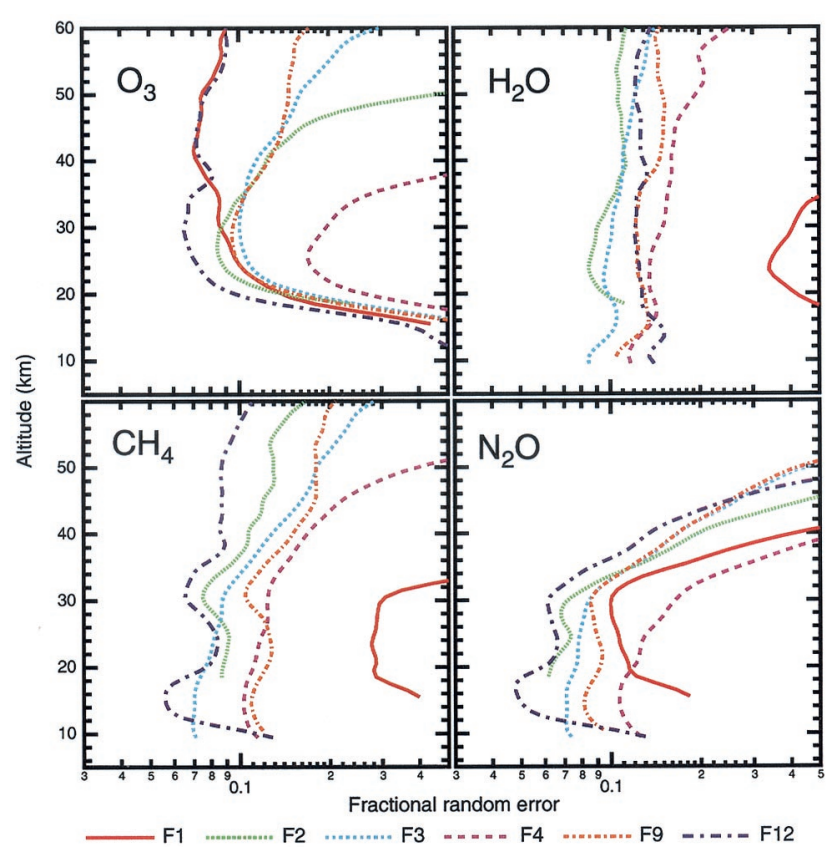

Fig. 10. Median random error for minor gases by filter for an individual occultation. 


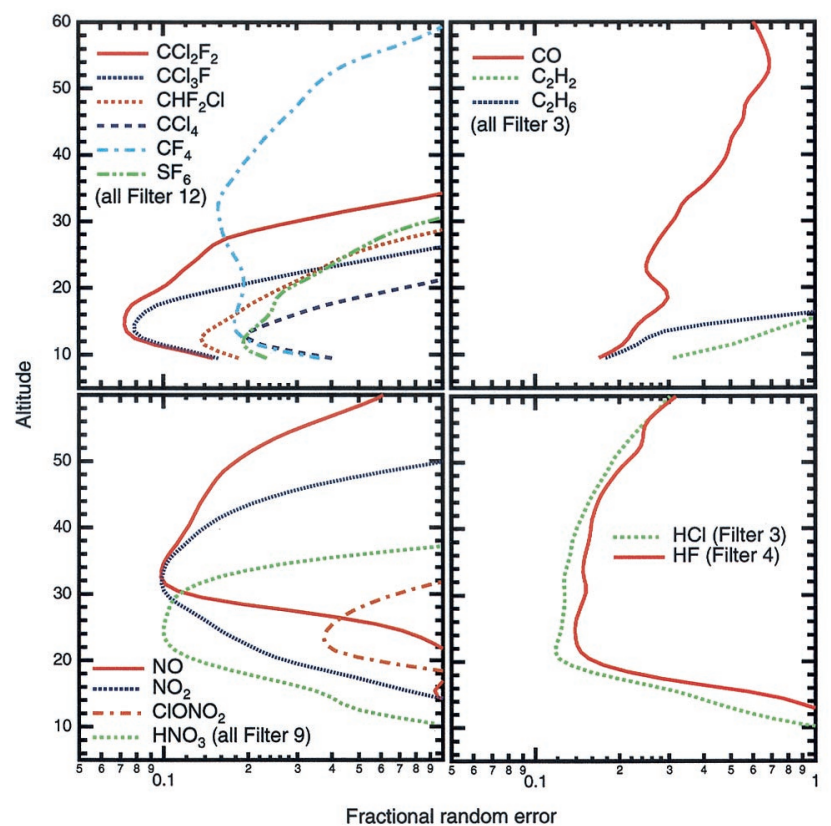

Fig. 11. Median random error for selected trace gases and spectral filters for an individual occultation.

ing were used in Version 3. The SNR of individual spectra is source noise limited, improves with either longer wavelengths or smaller spectral filter bandpasses, and decreases with increased atmospheric attenuation, particularly by the presence of moderateto-heavy aerosol loading or cloud cover.

The average SNRs for each spectral filter are listed in Table 1. Where possible the effect of noise error is reduced by (a) averaging retrievals over several spectral windows and/or using broad windows and (b) avoidance of spectra where the target lines have absorptions greater than 50\%. Generally spectra with SNRs of 60:1 or below were not used for analyses.

Within a fitted spectral window, uncertainties are calculated from the covariance matrix of the fitted parameters. These uncertainties are proportional to the rms fit over the window and inversely proportional to the depth and number of target-absorption features. As discussed in a study comparing colocated Fourier-transform spectrometers and spectral processing, ${ }^{6}$ the scheme used for Version 3 (GGG) results in uncertainties consistent with statistical scatter when the results are truly random. However, if residuals are dominated by systemic features that are consistent spectrum to spectrum, the uncertainties tend to be pessimistic. Details of Version 3 signal-to-noise error calculation are forthcoming. ${ }^{8}$

\section{Tangent-Pressure Uncertainty}

As described above the tangent pressure is determined by fitting $\mathrm{CO}_{2}$ and determining the pointing angle of the instrument (and therefore the tangent pressure and altitude) to match an assumed $\mathrm{CO}_{2}$ profile. We estimate the tangent-pressure random error as the quadrature sum of the fitting/SNR error in the retrieved column and an estimated error from the temperature-profile uncertainty. Errors in the retrieved $\mathrm{CO}_{2}$ column from the temperature uncertainty tend to be minor $(<2 \%)$ for all filters except filter 1. Because the $\mathrm{CO}_{2}$ lines used in filter 1 tend to have higher ground-state energies than those used in other filters, the temperature-uncertainty contribution tends to dominate the random error in filter 1 below $60 \mathrm{~km}$. Tangent-pressure uncertainties for each filter are illustrated in Fig. 9.

\section{Temperature-Profile Uncertainty}

As mentioned, spectral lines were chosen where possible to have ground-state energies of less than 400 $\mathrm{cm}^{-1}$; thus errors from temperature uncertainty are generally less than $3 \%$. Weaker high-J lines in a $\mathrm{P}$ or $\mathrm{R}$ branch used for minor gases, particularly $\mathrm{H}_{2} \mathrm{O}$, at lower-stratospheric and upper-tropospheric altitudes produced errors from temperature uncertainty of $\sim 7 \%$.

\section{Intensity Offset}

Interferograms must be corrected for the nonlinearity of the HgCdTe photoconducting detector of the ATMOS instrument; otherwise serious errors in zerolevel intensity offset will be introduced into the spectra. The error in gas retrieval significantly increases with either higher intensity offset or the absorption depth of a spectral feature. A combination of nonlinearity correction to the interferogram (reducing the zero-level intensity offset of the spectra to $\sim 1 \%$ ), as well as avoidance of spectra features of $50 \%$ or more absorption, keeps the intensity-offset error to no more than 3\%. A discussion of ATMOS detector nonlinearity corrections and their effect on retrievals is in Ref. 18.

\section{B. Systematic Errors}

Systematic errors include spectroscopic-parameter uncertainty, errors in the inversion technique, and error in the assumed $\mathrm{CO}_{2}$ profiles used to determine tangent altitudes. Unlike random error, calculation of systematic error for Version 3 is similar to that of Version 2. Estimated systematic errors for gases are in Table 2 and are similar to those in Ref. 5 .

\section{Spectroscopic-Parameter Uncertainty}

Generally, the largest source of systematic error in gas retrievals is the accuracy of the spectral-line intensities. As noted the spectral-line compilation used in Version 3 closely follows that described in Ref. 12 , where line parameters are discussed on a gas-bygas basis including line-intensity errors.

\section{Inversion Technique}

As discussed in Ref. 9, the previous retrieval algorithm was extensively intercompared with competing schemes with results agreeing to within 5\%. Comparison of Version 2 and Version 3 stratospheric retrievals is generally within this error. The Version 3 software used in analyzing MkIV interferometer data has been extensively intercompared with other algorithms in the analyses of ground-based solar- 
Table 2. Estimated Accuracy for Gas Retrievals

\begin{tabular}{|c|c|}
\hline Gas & Accuracy (\%) \\
\hline $\mathrm{H}_{2} \mathrm{O}$ & 6 \\
\hline $\mathrm{O}_{3}$ & 6 \\
\hline $\mathrm{N}_{2} \mathrm{O}$ & 5 \\
\hline $\mathrm{CO}$ & 5 \\
\hline $\mathrm{CH}_{4}$ & 5 \\
\hline $\mathrm{NO}^{a}$ & 5 \\
\hline $\mathrm{NO}_{2}{ }^{a}$ & 6 \\
\hline $\mathrm{HNO}_{3}$ & 16 \\
\hline $\mathrm{HF}$ & 5 \\
\hline $\mathrm{HCl}$ & 5 \\
\hline OCS & 9 \\
\hline $\mathrm{H}_{2} \mathrm{CO}$ & Undefined \\
\hline $\mathrm{HOCl}$ & 20 \\
\hline $\mathrm{H}_{2} \mathrm{O}_{2}$ & Undefined \\
\hline $\mathrm{HNO}_{4}$ & 20 \\
\hline $\mathrm{N}_{2} \mathrm{O}_{5}$ & 16 \\
\hline $\mathrm{ClONO}_{2}$ & 20 \\
\hline $\mathrm{HCN}$ & 6 \\
\hline $\mathrm{CH}_{3} \mathrm{Cl}$ & 11 \\
\hline $\mathrm{CF}_{4}$ & 11 \\
\hline $\mathrm{CCl}_{2} \mathrm{~F}_{2}$ & 9 \\
\hline $\mathrm{CCl}_{3} \mathrm{~F}$ & 11 \\
\hline $\mathrm{CCl}_{4}$ & 20 \\
\hline $\mathrm{COF}_{2}$ & 20 \\
\hline $\mathrm{C}_{2} \mathrm{H}_{6}$ & 11 \\
\hline $\mathrm{C}_{2} \mathrm{H}_{2}$ & 7 \\
\hline $\mathrm{CHClF}_{2}$ & 11 \\
\hline $\mathrm{HDO}$ & 7 \\
\hline $\mathrm{SF}_{6}$ & 11 \\
\hline $\mathrm{CH}_{3} \mathrm{D}$ & 7 \\
\hline
\end{tabular}

${ }^{a}$ Not including diurnal correction.

absorption spectra with very good agreement.6,19,20 A comparison of near colocated retrievals from MkIV balloonborne limb spectra and ER-2 aircraft in situ measurements were generally within $5 \% .{ }^{21} \mathrm{We}$ therefore believe that a systematic error of $5 \%$ is appropriate for the inversion technique.

\section{3. $\mathrm{CO}_{2}$ Profile}

Errors in the assumed $\mathrm{CO}_{2}$ profile will directly affect determination of a spectrum's tangent height and thus the retrieved VMR of other gases. Considering the latitudinal variability of $\mathrm{CO}_{2}$, and differences in the stratospheric and tropospheric mixing ratios, we estimate that assumed $\mathrm{CO}_{2}$ mixing ratios may be in error by as much as 5 parts per million by volume (ppmv) in the free troposphere. This, in addition to an estimated error of 2-3\% in the spectral intensities of the $\mathrm{CO}_{2}$ lines, ${ }^{12}$ translates into a rms systematic error of $\sim 4 \%$ in retrieved tangent pressures and VMR. The retrieval software was configured such that only the ${ }^{16} \mathrm{O}^{12} \mathrm{C}^{16} \mathrm{O}\left({ }^{44} \mathrm{CO}^{2}\right)$ isotopomer was used except for the region from 1200 to $1400 \mathrm{~cm}^{-1}$ where the weaker absorptions of ${ }^{18} \mathrm{O}^{12} \mathrm{C}^{16} \mathrm{O}$ were used at lower stratospheric and tropospheric altitudes owing to a lack of unsaturated ${ }^{44} \mathrm{CO}_{2}$ lines. This introduces an additional systematic bias at tropospheric altitudes for filters 2,9 , and 12 of $\sim 4 \%$ in the tangentpressure determination because of isotopic enrich- ments relative to standard mean ocean water. Although this enrichment is known to increase in the stratosphere (e.g., Ref. 22), the effect on tangentpressure determination is less as $\mathrm{CO}_{2}$ retrievals become more weighted to comparatively stronger but unsaturated ${ }^{44} \mathrm{CO}_{2}$ lines.

\section{Results}

In this section we discuss selected results for key trace and minor species from the Version 3 processing of the ATMOS data. Here Version 3 results are mostly compared with those of Version 2. Elsewhere, however, Version 3 results have been compared with other instruments for $\mathrm{H}_{2} \mathrm{O},{ }^{23-26}$ $\mathrm{H}_{2} \mathrm{O}+2 \mathrm{CH}_{4},{ }^{23-25} \mathrm{O}_{3},{ }^{27,28} \mathrm{HCl},{ }^{27,29}$ and $\mathrm{ClONO}_{2}, \mathrm{NO}_{\mathrm{x}}$, $\mathrm{NO}_{\mathrm{y}}, \mathrm{N}_{2} \mathrm{O}$, and $\mathrm{CH}_{4} \cdot{ }^{27}$ Version 3 results have been compared with models for $\mathrm{CO},{ }^{30} \mathrm{~N}_{2} \mathrm{O}, \mathrm{CH}_{4}, \mathrm{H}_{2} \mathrm{O}$, and $\mathrm{O}_{3},{ }^{28,31} \mathrm{HCl},{ }^{27,29}$ and $\mathrm{ClONO}_{2}, \mathrm{HNO}_{3}$, and $\mathrm{NO}_{x} \cdot{ }^{27}$

\section{A. Tropospheric/Stratospheric Chlorine and Fluorine Budgets}

The currently accepted understanding of $\mathrm{Cl}$ loading in the atmosphere is that (a) the emissions of longlived Cl-bearing source gases (both natural and anthropogenic), whose total Cl-atom sum is defined as $\mathrm{CCl}_{y}$, are located at the ground and mix into the global troposphere. (b) Primarily at tropical latitudes they are progressively lifted above the tropopause and are transported throughout the stratosphere where (c) photodissociation by solar UV radiation decomposes them, with (d) the resulting formation of inorganic sinks and reservoirs whose total Cl-atom sum is defined as $\mathrm{Cl}_{y}$. Therefore the total atmospheric chlorine loading $\mathrm{Cl}_{\text {tot }}$ at any altitude can be defined as

$$
\mathrm{Cl}_{\text {tot }}=\left[\mathrm{CCl}_{y}\right]+\left[\mathrm{Cl}_{y}\right] .
$$

To within $\approx 3 \%$ the main sources contributing to $\mathrm{CCl}_{y}$ are $\mathrm{CH}_{3} \mathrm{Cl}, \mathrm{CCl}_{2} \mathrm{~F}_{2}, \mathrm{CCl}_{3} \mathrm{~F}, \mathrm{CHClF}_{2}, \mathrm{CCl}_{4}$, $\mathrm{CH}_{3} \mathrm{CCl}_{3}$, and $\mathrm{C}_{2} \mathrm{Cl}_{3} \mathrm{~F}_{3}$, while $\mathrm{Cl}_{y}$ is approximated to within a similar uncertainty by combining the contributings from $\mathrm{HCl}, \mathrm{ClONO}_{2}, \mathrm{ClO}$, and $\mathrm{HOCl}$ (except for the polar lower stratosphere where the $\mathrm{ClO}$ dimer plays a significant role).

Similarly, the total atmospheric fluorine loading $\mathrm{F}_{\text {tot }}$ is defined as

$$
\mathrm{F}_{\mathrm{tot}}=\left[\mathrm{CF}_{y}\right]+\left[\mathrm{F}_{y}\right],
$$

which primarily involves contributions to $\mathrm{CF}_{y}$ by $\mathrm{CCl}_{2} \mathrm{~F}_{2}, \mathrm{CCl}_{3} \mathrm{~F}, \mathrm{CHCIF}_{2}, \mathrm{CF}_{4}, \mathrm{C}_{2} \mathrm{Cl}_{3} \mathrm{~F}_{3}$, and $\mathrm{SF}_{6}$ and to $\mathrm{F}_{y}$ by $\mathrm{HF}, \mathrm{COF}_{2}$, and $\mathrm{COFCl}$.

Based on simultaneous or near-simultaneous ATMOS measurements of a large number of the species listed above, stratospheric budgets of $\mathrm{Cl}_{\text {tot }}$ and $\mathrm{F}_{\text {tot }}$ were readily derived for the 1985 Spacelab 3 mission $^{32}$ and of $\mathrm{Cl}_{\text {tot }}$ for the 1994 ATLAS 3 Shuttle flight, ${ }^{33}$ all results and conclusions regarding these budgets remain valid. Version 3 data, however, allow these earlier investigations to be extended farther down into the troposphere, as shown in Figs. 12 and 13. The important source gases, i.e., $\mathrm{CCl}_{2} \mathrm{~F}_{2}$, 


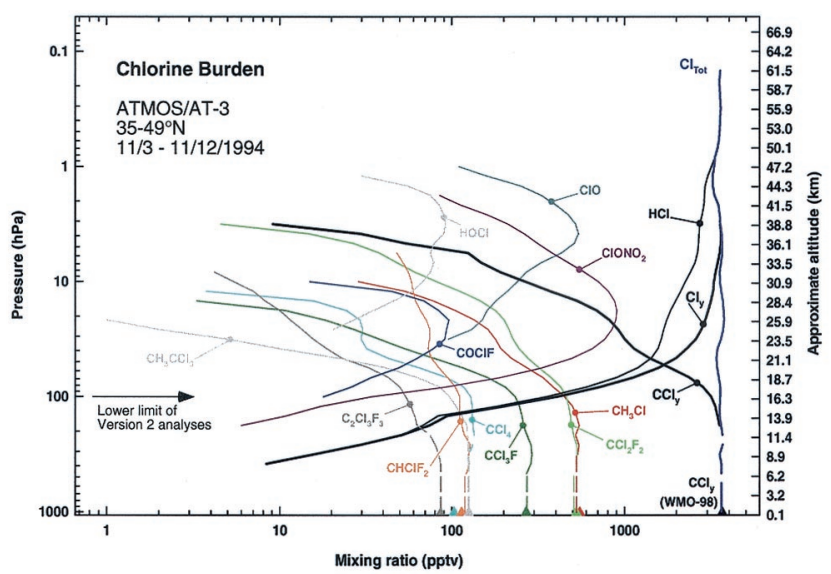

Fig. 12. Northern-latitude zonal average VMR profiles of chlorinated species from ATMOS Version 3, ATLAS-3 retrievals. Species not measured by ATMOS are in gray. The horizontal arrow indicates the level down to which Version 2 profiles could be reliably retrieved. Triangles on the bottom scale correspond to the measured in situ ground VMRs.

$\mathrm{CCl}_{3} \mathrm{~F}, \mathrm{CHClF}_{2}$, and $\mathrm{CH}_{3} \mathrm{Cl}$, contributing to $\mathrm{CCl}_{y}$ and/or $\mathrm{CF}_{y}$, can be retrieved down to nearly $6 \mathrm{~km}$ at northern mid-latitudes. Clearly such downward extensions of the VMR profiles allow a better comparison with tropospheric in situ measurements. For the four gases just listed this agreement is very good, well within the combined uncertainties of both techniques. ${ }^{34}$ One noticeable discrepancy remains with $\mathrm{CCl}_{4}$ whose VMR in the vicinity of the tropopause $[\sim 130$ parts per trillion by volume (pptv)] is substantially larger than the in situ concentration at the ground (102-104 pptv); this discrepancy was also present for ATMOS Version 2 results when compared with those from a gas chromatograph operated aboard an ER-2 during the Airborne Southern Hemisphere Experiment/Measurements for Assessing the

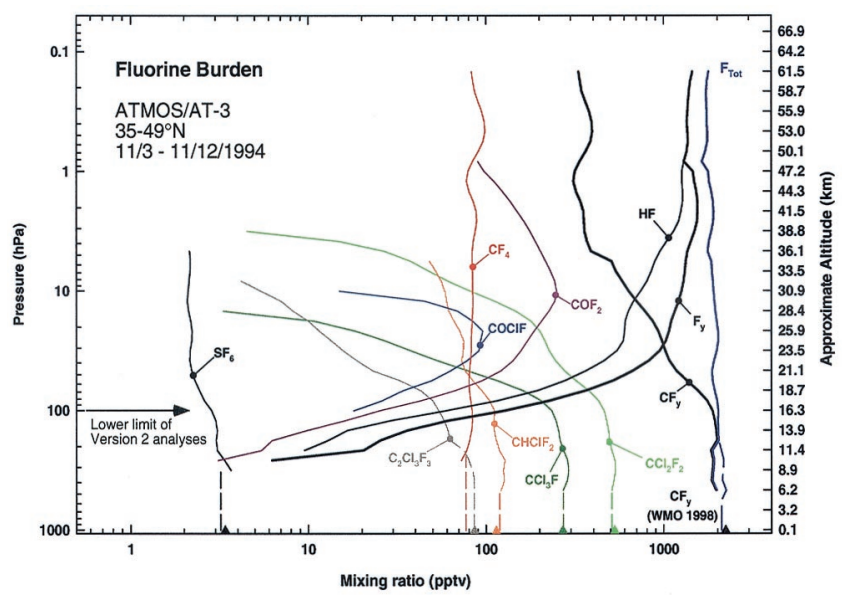

Fig. 13. Profiles of the northern-latitude zonal average mixing ratio of fluorinated species from ATMOS Version 3, ATLAS-3 retrievals. Species not measured by ATMOS are in gray. The horizontal arrow indicates the level down to which Version 2 profiles could be reliably retrieved. Triangles on the bottom scale correspond to the measured in situ ground VMR's.

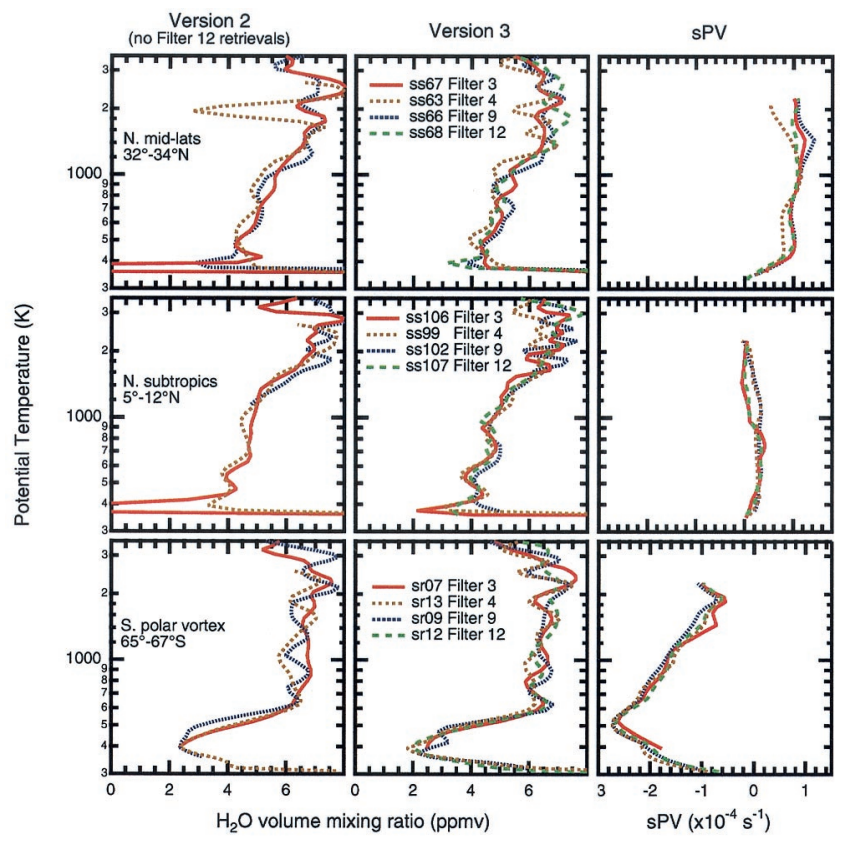

Fig. 14. Comparison of selected retrievals of $\mathrm{H}_{2} \mathrm{O}$. The upper row illustrates northern mid-latitude retrievals, the middle row shows northern tropic and subtropic retrievals, while the bottom row shows retrievals from within the Antarctic polar vortex. The left column shows Version 2 retrievals, the middle column shows Version 3 retrievals, and the right column shows sPV profiles for each retrieval. Note that Version 3 retrievals avoid unrealistically low mixing ratios near the tropopause. Reasonable consistency is maintained in Version 3 across spectral filters, including filter 12 , for which $\mathrm{H}_{2} \mathrm{O}$ retrievals are new.

Effects of Stratospheric Aircraft campaign, ${ }^{35,36}$ it may be caused by line mixing in a strong $\mathrm{CO}_{2} Q$ branch interfering with the ATMOS-adopted $\mathrm{CCl}_{4}$ microwindow at $785-807 \mathrm{~cm}^{-1}$.

The Version $3 \mathrm{VMR}$ profiles of $\mathrm{HCl}, \mathrm{HF}$, and $\mathrm{SF}_{6}$, have also been extended to as high as the $62-\mathrm{km}$ altitude, whereas Version 2 retrievals reached $55 \mathrm{~km}$ at best. ${ }^{32,33}$ This allows a better estimation of the $\mathrm{HCl}$ and $\mathrm{HF}$ VMRs in the vicinity of the stratopause. These are good surrogates of the total chlorine and fluorine loadings. ${ }^{37}$

B. $\mathrm{H}_{2} \mathrm{O}$ and $\mathrm{H}_{2} \mathrm{O}+2 \mathrm{CH}_{4}$

In Fig. 14 selected Version 2 and $3 \mathrm{H}_{2} \mathrm{O}$ profiles are compared. For illustrative purposes, profiles are compared from different spectral filters, but these were observed in similar air masses (as measured by potential temperature and a scaled potential vorticity; see Ref. 24 or 28). Version 3 profiles, both in Fig. 14 and in general, avoid the unrealistically low neartropopause $\mathrm{H}_{2} \mathrm{O}$ mixing ratios often seen in Version 2. More important, for purposes of upperstratospheric water the Version $3 \mathrm{H}_{2} \mathrm{O}$ retrievals in filter 12 (which were not done for Version 2) are consistent with other filters, including filter 4 with which it has no spectral windows in common. There is better internal consistency as well as an improved agreement with the Halogen Occultation Experiment 


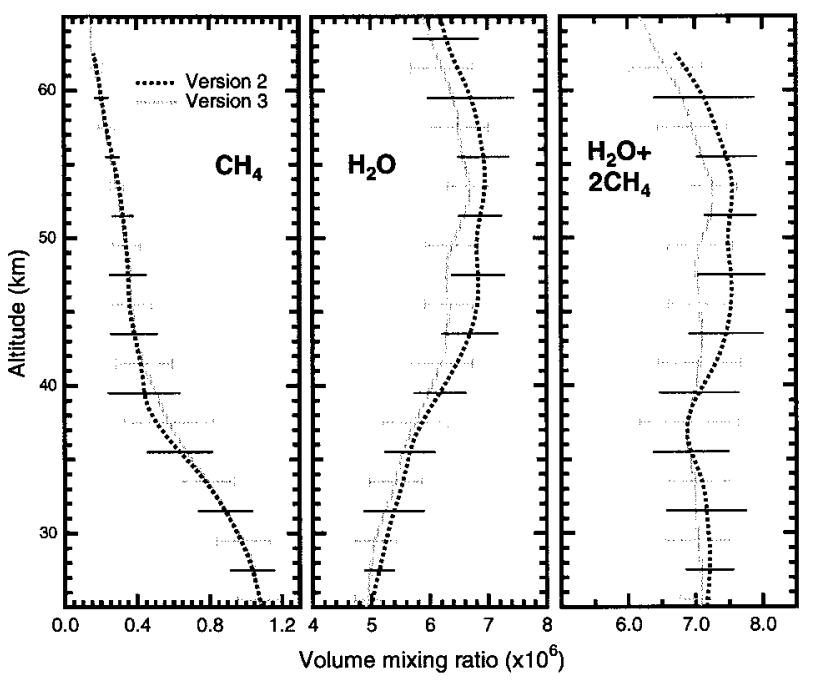

Fig. 15. Profiles of zonal average mixing ratios of $\mathrm{CH}_{4}, \mathrm{H}_{2} \mathrm{O}$, and the sum $\mathrm{H}_{2} \mathrm{O}+2 \mathrm{CH}_{4}$ from ATMOS Versions 2 and 3 retrievals. A total of 34 sunset occultations between 31 and $49^{\circ} \mathrm{N}$ (filters 3 and 9) from the ATLAS-3 missions were used. Error bars are standard deviations weighted by the inverse square error of the individual retrievals.

(HALOE), Millimeter-wave Atmospheric Sounder (MAS), and Microwave Limb Sounder (MLS). ${ }^{24}$

The only significant stratospheric reservoirs for hydrogen are $\mathrm{H}_{2} \mathrm{O}, \mathrm{CH}_{4}$, and $\mathrm{H}_{2}$. Oxidations of $\mathrm{CH}_{4}$ and $\mathrm{H}_{2}$ are the only significant local sources of $\mathrm{H}_{2} \mathrm{O}$, so changes in the sum $\left[\mathrm{H}_{2} \mathrm{O}\right]+2\left[\mathrm{CH}_{4}\right]$ are indicative of changes in $\mathrm{H}_{2}$ (where [] is the VMR). In the absence of dehydration and if the stratospheric mixing ratio of $\mathrm{H}_{2}$ is a constant, the sum $\left[\mathrm{H}_{2} \mathrm{O}\right]+2\left[\mathrm{CH}_{4}\right]$ in a stratospheric air mass should be the same as when it entered the stratosphere, and $\partial\left[\mathrm{H}_{2} \mathrm{O}\right] / \partial\left[\mathrm{CH}_{4}\right]=-2$ above the hygropause in extratropical and extravortex air masses; deviations from this relationship indicate a net production or destruction of $\mathrm{H}_{2}$. A previous analysis of the data of ATMOS Version 2 showed a broad maximum for $\left[\mathrm{H}_{2} \mathrm{O}\right]+2\left[\mathrm{CH}_{4}\right]$ between 35 and $65 \mathrm{~km}$ in northern-latitude extratropical retrievals, evidence for a net oxidation of $\mathrm{H}_{2}$ to $\mathrm{H}_{2} \mathrm{O}^{38}$ However, as discussed in Ref. 24 and illustrated in Fig. 15, a comparison of Version 2 and 3 results shows lower VMR for stratospheric water in this region for Version 3, while the VMRs for $\mathrm{CH}_{4}$ are effectively unchanged. The sum $\left[\mathrm{H}_{2} \mathrm{O}\right]+2\left[\mathrm{CH}_{4}\right]$ is nearly constant throughout the extratropical stratosphere to $\sim 55 \mathrm{~km}$; thus these Version 3 analyses provide no evidence for net changes in $\mathrm{H}_{2}$ in the upper stratosphere. An analysis of the $\mathrm{H}_{2} \mathrm{O}$ retrieval process between Versions 2 and 3 indicated that a combination of modified spectral windows, slightly lower tangent heights above $30 \mathrm{~km}$, and algorithmic changes in Version 3 all contributed to the lower $\mathrm{H}_{2} \mathrm{O}$ mixing ratios compared with Version 2.

C. $\mathrm{NO}, \mathrm{NO}_{2}$, and $\mathrm{CO}$

In Fig. $16 \mathrm{NO}, \mathrm{NO}_{2}$, and $\mathrm{CO}$, is compared between Versions 2 and 3 . The profiles are averages of

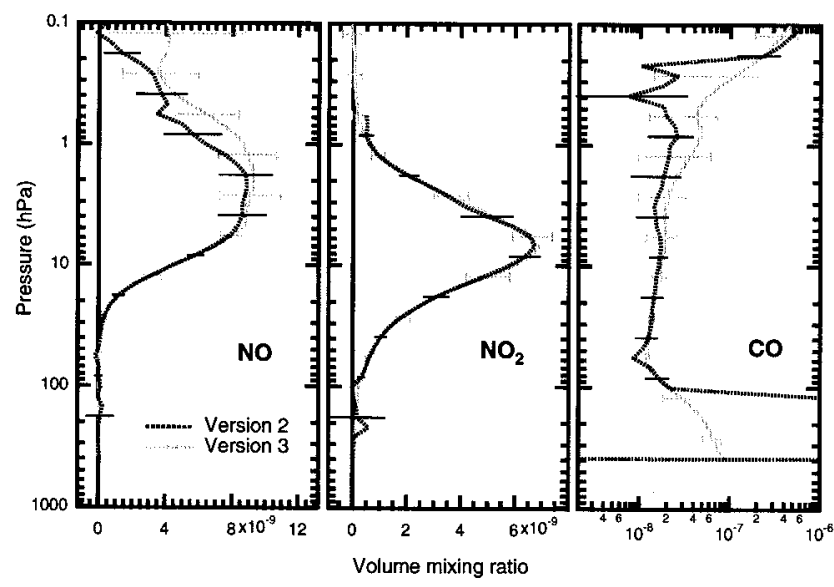

Fig. 16. Comparison of the VMRs of $\mathrm{NO}, \mathrm{NO}_{2}$, and $\mathrm{CO}$ of Versions 2 and 3, filter 3. Average VMRs are from ATLAS-3 northern protovortex retrievals. The error bars are standard deviations weighted by the inverse square signal-to-noise/fitting error.

ATLAS-3 Filter 3 retrievals in the developing Arctic vortex (the protovortex). ${ }^{39,40}$ To simplify comparison, profiles are shown without diurnal corrections. For all three gases the averages in Version 3 appear to be somewhat smoother than Version 2. There is good agreement for $\mathrm{NO}_{2}$, while for $\mathrm{NO}$ and $\mathrm{CO}$ higher mixing ratios are seen above $5 \mathrm{hPa}$, although the standard deviations tend to overlap. In the troposphere, retrievals of $\mathrm{CO}$ are much more realistic in Version 3 than Version 2. Statistically significant retrievals of $\mathrm{NO}$ and $\mathrm{NO}_{2}$ were often difficult to obtain in the troposphere. With the possible exception of elevated regions of tropospheric $\mathrm{NO}$ or $\mathrm{NO}_{2}(>100$ pptv), Version 3 results may provide only an upper limit of these gases in the troposphere.

D. $\mathrm{HNO}_{3}$

In a manner similar to $\mathrm{H}_{2} \mathrm{O}$, Fig. 17 presents sample $\mathrm{HNO}_{3}$ retrievals from Version 2 and 3 across filters 3 , 9 , and 12 selected for similar scaled potential vorticity (sPV) profiles. Version 3 results reflect increased mixing ratios of $\sim 10 \%$ over Version 2 because of changes in the line strengths described in Subsection 2.D.2.

\section{E. Aerosol Measurements}

A new product in the Version 3 ATMOS data set is stratospheric sulfuric-acid aerosol volume. Vertical profiles of the volume of aerosol composed of sulfuric acid and water are retrieved by using the broad spectral features of sulfuric-acid absorption. When data from filter 1,9 , or 12 in the spectral region of $800-$ $1250 \mathrm{~cm}^{-1}$ are used, the aerosol retrievals are most sensitive to total aerosol volume and the weight percent of sulfuric acid. These retrievals are relatively insensitive to the aerosol size distribution. Aerosol volume peaks in the lower stratosphere (near 18-20 $\mathrm{km}$ ) and ranges from 2 to $3 \mu \mathrm{m}^{3} \mathrm{~cm}^{-3}$ (with approximately $1-15 \%$ error) in 1992 to values closer to $0.3-$ $0.6 \mathrm{\mu m}^{3} \mathrm{~cm}^{-3}$ (with an error of 5-30\%) in 1994. This reduction in aerosol volume was widely documented 


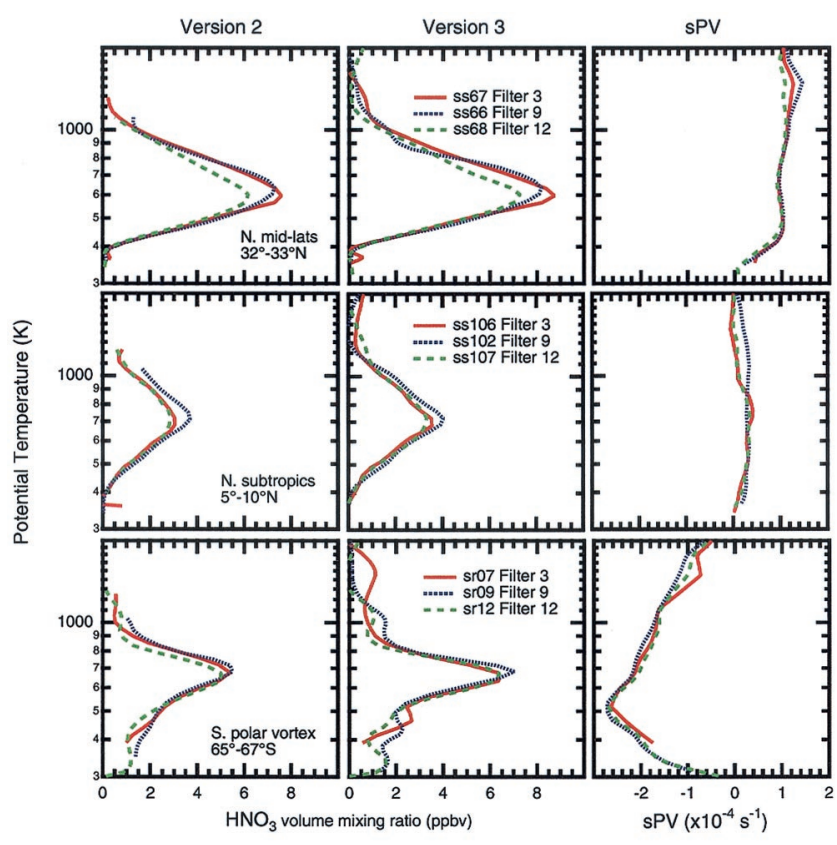

Fig. 17. Comparison of selected retrievals of $\mathrm{HNO}_{3}$. The upper row shows northern mid-latitude retrievals, the middle row shows northern tropic and subtropic retrievals, while the bottom row shows retrievals from within the Antarctic polar vortex. The left column shows Version 2 retrievals, the middle column shows Version 3 retrievals, and the right column shows sPV profiles for each retrieval. Version 3 retrievals tend to be larger owing to modifications in the $\mathrm{HNO}_{3}$ spectral strengths (see text).

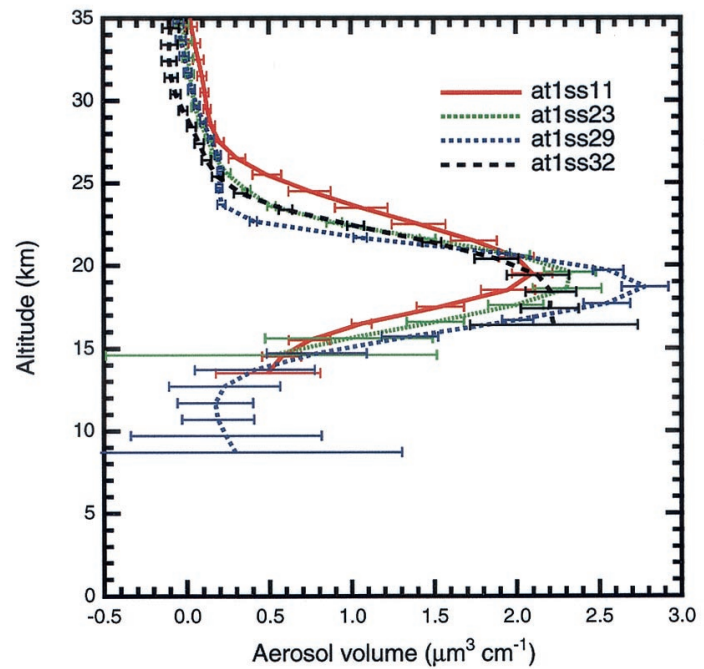

Fig. 18. Vertical profiles of stratospheric sulfurio-acid aerosol for a set of ATLAS-1 filter 9 occultations taken over the southern tip of South America in 1992. Altitudes of different profiles have been slightly offset from one another for clarity.

in the years following the eruption of Mt. Pinatubo. ${ }^{41-44}$ Four vertical profiles taken in 1992 in the same region are shown in the Fig. 18. A complete discussion of the retrieval methodology is in Ref. 45.

\section{Conclusions}

Version 3 of the ATMOS data set, containing retrievals of the volume mixing ratio of some 30 stratospheric and upper-tropospheric species, has been described. The global-fit methodology of Version 3 requires significantly more computing resources than the computationally faster onion-peel algorithm of Version 2, but the increased reliability in tropospheric retrievals by the former technique merits its use. Compared with Version 2, results have been more reliably extended to tropospheric altitudes and in some cases (e.g., $\mathrm{HCl}$ and $\mathrm{HF}$ ) also to higher altitudes. There has been significant improvement in retrievals of upper-tropospheric/lower-stratospheric $\mathrm{H}_{2} \mathrm{O}$ and $\mathrm{CO}$, but more reliable retrievals have also been made for minor gases such as $\mathrm{CH}_{4}$ and $\mathrm{N}_{2} \mathrm{O}$ and short-lived species such as $\mathrm{C}_{2} \mathrm{H}_{2}$ and $\mathrm{C}_{2} \mathrm{H}_{6}$. General agreement is maintained for stratospheric retrievals between Versions 2 and 3, although there are some differences. Version $3 \mathrm{HNO}_{3}$ is $\sim 10 \%$ higher than that of Version 2. Upper-stratospheric water vapor is slightly lower in Version 3 but shows better consistency across the ATMOS spectral filters. Unlike Version 2, Version 3 results show the sum $\left[\mathrm{H}_{2} \mathrm{O}\right]+$ $2\left[\mathrm{CH}_{4}\right]$ to be constant in the upper stratosphere to $\sim 55 \mathrm{~km}$ and do not suggest any net consumption of $\mathrm{H}_{2}$. A new product for sulfuric-acid aerosol retrieval has been described, and initial results show the expected decrease in stratospheric sulfuric-acid aerosol in the years following the Mt. Pinatubo eruption. Version 3 retrievals are available at http://atmos. jpl.nasa.gov/atmos.

Research on additional gas and aerosol retrievals and validation of current results continue. An improvement to the processing methodology can be made in the zenith angle/pressure-sounding determination by using assumed a priori $\mathrm{CO}_{2}$ profiles more appropriate to a tangent latitude and season as well as compensating for isotopic enrichments in ${ }^{18} \mathrm{O}^{12} \mathrm{C}^{16} \mathrm{O}$ in spectral regions where use of ${ }^{16} \mathrm{O}^{12} \mathrm{C}^{16} \mathrm{O}$ cannot be made. Additional improvement to the zenith-angle determination for tropospheric spectra can be made by including water vapor in refraction calculations, although this would likely require an $\mathrm{H}_{2} \mathrm{O}$ mixing ratio/zenith-angle retrieval iterative loop. With advancements in algorithms and spectroscopic databases, the richness of broadband, highresolution IR spectra from space allows continual increase in the quality and number of products from even old data sets.

This effort builds on the work of past and present science and processing team members of the ATMOS experiment. We thank them and in particular C. B. Farmer, M. C. Abrams, and the late R. H. Norton. Research at the Jet Propulsion Laboratory, California Institute of Technology, was performed under contract to NASA.

\section{References}

1. C. B. Farmer, O. F. Raper, and F. G. O'Callaghan, "Final report on the first flight of the ATMOS instrument during the 
Spacelab 3 mission, April 29 through May 6, 1985," JPL publication 87-32 (Jet Propulsion Laboratory, Pasadena, Calif., 1987).

2. M. R. Gunson, M. M. Abbas, M. C. Abrams, M. Allen, L. R. Brown, T. L. Brown, A. Y. Chang, A. Goldman, F. W. Irion, L. L. Lowes, E. Mahieu, G. L. Manney, H. A. Michelsen, M. J. Newchurch, C. P. Rinsland, R. J. Salawitch, G. P. Stiller, G. C. Toon, Y. L. Yung, and R. Zander, "The Atmospheric Trace Molecule Spectroscopy (ATMOS) experiment: deployment on the ATLAS Space Shuttle missions," Geophys. Res. Lett. 23, 2333-2336 (1996).

3. R. H. Norton and C. P. Rinsland, "ATMOS data processing and science analysis methods,” Appl. Opt. 30, 389-400 (1991).

4. M. C. Abrams, M. R. Gunson, A. Y. Chang, C. P. Rinsland, and R. Zander, "Remote sensing of the Earth's atmosphere from space with high-resolution Fourier-transform spectroscopy: development and methodology of data processing for the Atmospheric Trace Molecule Spectroscopy experiment," Appl. Opt. 35, 2774-2786 (1996).

5. M. C. Abrams, A. Y. Chang, M. R. Gunson, M. M. Abbas, A. Goldman, F. W. Irion, H. A. Michelsen, M. J. Newchurch, C. P. Rinsland, G. P. Stiller, and R. Zander, "On the assessment and uncertainty of atmospheric trace gas burden measurements with high resolution infrared solar occultation spectra from space by the ATMOS experiment," Geophys., Res. Lett. 23, 2337-2340 (1996).

6. A. Goldman, C. Paton-Walsh, W. Bell, G. C. Toon, J.-F. Blavier, B. Sen, M. T. Coffey, J. W. Hannigan, and W. G. Mankin, "Network for the detection of stratospheric change Fouriertransform infrared intercomparison at Table Mountain Facility, November 1996,” J. Geophys. Res. 104, 30481-30503 (1999).

7. G. C. Toon, "The JPL MkIV interferometer," Opt. Photon. News 2(10), 19-21 (1991).

8. G. C. Toon, J.-F. Blavier, and B. Sen are preparing a manuscript titled, "Balloon-borne FTIR solar absorption spectrometry for measurements of atmospheric composition."

9. M. R. Gunson, C. B. Farmer, R. H. Norton, R. Zander, C. P. Rinsland, J. H. Shaw, and B.-C. Gao, "Measurements of $\mathrm{CH}_{4}$, $\mathrm{N}_{2} \mathrm{O}, \mathrm{CO}, \mathrm{H}_{2} \mathrm{O}$, and $\mathrm{O}_{3}$ in the middle atmosphere by the Atmospheric Trace Molecule Spectroscopy experiment on Spacelab 3,” J. Geophys. Res. 95, 13867-13882 (1990).

10. G. P. Stiller, M. R. Gunson, L. L. Lowes, M. C. Abrams, O. F. Raper, C. B. Farmer, R. Zander, and C. P. Rinsland, "Stratospheric and mesospheric pressure-temperature profiles from rotational analysis of $\mathrm{CO}_{2}$ lines in atmospheric trace molecule spectroscopy/ATLAS 1 infrared solar occultation spectra," J. Geophys. Res. 100, 3107-3117 (1995).

11. M. López-Puertas, M. A. López-Valverde, C. P. Rinsland, and M. R. Gunson, "Analysis of the upper atmospheric $\mathrm{CO}_{2}\left(v_{2}\right)$ vibrational temperatures retrieved from ATMOS/Spacelab 3 observations,” J. Geophys. Res. 97, 20469-20478 (1992).

12. L. R. Brown, M. R. Gunson, R. A. Toth, F. W. Irion, C. P. Rinsland, and A. Goldman, "The 1995 Atmospheric Trace Molecule Spectroscopy (ATMOS) linelist," Appl. Opt. 35, 28282848 (1996).

13. A. Goldman, C. P. Rinsland, A. Perrin, and J. M. Flaud, " $\mathrm{HNO}_{3}$ line parameters: 1996 HITRAN update and new results," J. Quant. Spectrosc. Radiat. Transfer 60, 851-861 (1998).

14. L. S. Rothman, C. P. Rinsland, A. Goldman, S. T. Massie, D. P. Edwards, J. M. Flaud, A. Perrin, C. Camy-Peyret, V. Dana, J. Y. Mandin, J. Schroeder, A. McCann, R. R. Gamache, R. B. Wattson, K. Yoshino, K. V. Chance, K. W. Jucks, L. R. Brown, V. Nemtchinov, and P. Varanasi, "The HITRAN molecular spectroscopic database and HAWKS (HITRAN Atmospheric Workstation): 1996 edition,” J. Quant. Spectrosc. Radiat. Transfer 60, 665-710 (1998).

15. A. Nikitin, J. P. Champion, V. G. Tyuterev, L. R. Brown, G.
Mellau, and M. Lock, "The infrared spectrum of $\mathrm{CH}_{3} \mathrm{D}$ between 900 and $3200 \mathrm{~cm}^{-1}$ : extended assignment and modeling," J. Mol. Struct. 517, 1-24 (2000).

16. M. J. Newchurch, M. Allen, M. R. Gunson, R. J. Salawitch, G. B. Collins, K. H. Huston, M. M. Abbas, M. C. Abrams, A. Y. Chang, D. W. Fahey, R. S. Gao, F. W. Irion, M. Lowenstein, G. L. Manney, H. A. Michelsen, J. R. Podolske, C. P. Rinsland, and R. Zander, "Stratospheric $\mathrm{NO}$ and $\mathrm{NO}_{2}$ abundances from ATMOS solar-occultation measurements," Geophys. Res. Lett. 23, 2373-2376 (1996).

17. B. Sen, G. C. Toon, G. B. Osterman, J.-F. Blavier, J. J. Margitan, and R. J. Salawitch, "Measurements of reactive nitrogen in the stratosphere," J. Geophys. Res. 103, 3571-3585 (1998).

18. M. C. Abrams, G. C. Toon, and R. A. Schindler, "Practical example for the correction of Fourier-transform spectra for detector nonlinearity," Appl. Opt. 33, 6307-6314 (1994).

19. A. Goldman, "Intercomparison of analysis of ground-based IR synthetic spectra," presented at NDSC Infrared Working Group Meeting, Network for Detection of Stratospheric Change, Garmisch, Germany, 23-25 April (1996).

20. R. Zander, Ph. Demoulin, E. Mahieu, G. P. Adrian, C. P. Rinsland, and A. Goldman, "ESMOSII/NDSC IR spectral fitting algorithms intercomparison exercise," in Proceedings of the Atmospheric Spectroscopy Applications Workshop, A. Barbe and L. Rothman, eds. (University of Reims Champaigne, Ardenne, 1993).

21. G. C. Toon, J.-F. Blavier, B. Sen, J. J. Margitan, C. R. Webster, R. D. May, D. Fahey, R. Gao, L. Del Negro, M. Proffitt, J. Elkins, P. A. Romashkin, D. F. Hurst, S. Oltmans, E. Atlas, S. Schauffler, F. Flocke, T. P. Bui, R. M. Stimpfle, G. P. Bonne, P. B. Voss, and R. C. Cohen, "Comparison of MkIV balloon and ER-2 aircraft measurements of atmospheric trace gases," J. Geophys. Res. 104, 26,779-26,790 (1999).

22. Y. L. Yung, A. Y. T. Lee, F. W. Irion, W. B. DeMore, and J. Wen, "Carbon dioxide in the atmosphere: isotope exchange with ozone and its use as a tracer in the middle atmosphere," J. Geophys. Res. 102, 10,857-10,866 (1997).

23. H. A. Michelsen, F. W. Irion, G. L. Manney, G. C. Toon, and M. R. Gunson, "Features and trends in Atmospheric Trace Molecule Spectroscopy (ATMOS) Version 3 stratospheric water vapor and methane measurements," J. Geophys. Res. 105, 22,713-22,724 (2000).

24. H. A. Michelsen, G. L. Manney, F. W. Irion, G. C. Toon, M. R. Gunson, C. P. Rinsland, R. Zander, E. Mahieu, M. J. Newchurch, P. N. Purcell, E. E. Remsberg, J. M. Russell III, H. C. Pumphrey, J. W. Waters, R. M. Bevilacqua, K. K. Kelly, E. J. Hinsta, E. M. Weinstock, E.-W. Chiou, W. P. Chu, M. P. McCormick, and C. R. Webster, "ATMOS Version 3 water vapor measurements: comparisons with ATMOS Version 2 retrievals and observations from two ER-2 Lyman- $\alpha$ hygrometers, MkIV, HALOE, SAGE II, MAS, and MLS," J. Geophys. Res. 107, 10.1029/2001JD000587 (2002).

25. Stratospheric Processes and their Role in Climate (SPARC), "Assessment of upper tropospheric and stratospheric water vapor," WCRP-113, WMO/TD-1043 (World Climate Research Programme of World Meterological Organization/International Council for Science, Paris, France, 2000).

26. K. H. Rosenlof, S. J. Oltmans, D. Kley, J. M. Russell III, E.-W. Chiou, W. P. Chu, D. G. Johnson, K. K. Kelly, H. A. Michelsen, G. E. Nedoluha, E. E. Remsberg, G. C. Toon, and M. P. McCormick, "Stratospheric water vapor increases over the past half-century," Geophys. Res. Lett. 28, 1195-1198 (2001).

27. H. A. Michelsen, C. R. Webster, G. L. Manney, D. C. Scott, J. J. Margitan, R. D. May, F. W. Irion, M. R. Gunson, J. M. Russell III, and C. M. Spivakovsky, "Maintenance of high $\mathrm{HCl} / \mathrm{Cl}_{y}$ and $\mathrm{NO}_{x} / \mathrm{NO}_{y}$ in the Antarctic vortex: a chemical signature of confinement during spring," J. Geophys. Res. 104, 26,41926,436 (1999). 
28. G. L. Manney, H. A. Michelsen, R. M. Bevilacqua, M. R. Gunson, F. W. Irion, N. J. Livesey, J. Oberheide, M. Riese, J. M. Russell III, G. C. Toon, and J. M. Zawodny, "Comparison of ozone observations in early November 1994 in the context of meterological variability," J. Geophys. Res. 106, 9923-9943 (2001).

29. C. R. Webster, H. A. Michelsen, M. R. Gunson, J. J. Margitan, J. M. Russell, G. C. Toon, and W. A. Traub, "Response of lower stratospheric $\mathrm{HCl} / \mathrm{Cl}_{y}$ to volcanic aerosol: observations from aircraft balloon, Space Shuttle, and satellite instruments," J. Geophys. Res. 105, 11,711-11,719 (2000).

30. C. P. Rinsland, R. J. Salawitch, G. B. Osterman, F. W. Irion, B. Sen, R. Zander, E. Mahieu, and M. R. Gunson, "Stratospheric $\mathrm{CO}$ at tropical and mid-latitudes: ATMOS measurements and photochemical steady-state model calculations," Geophys. Res. Lett. 27, 1395-1398 (2000).

31. G. L. Manney, H. A. Michelsen, F. W. Irion, G. C. Toon, M. R. Gunson, and A. E. Roche, "Lamination and polar vortex development in fall from ATMOS long-lived trace gases observed during November 1994," J. Geophys. Res. 105, 29,023-29,038 (2000).

32. R. Zander, M. R. Gunson, C. B. Farmer, C. P. Rinsland, F. W. Irion, and E. Mahieu, "The 1985 chlorine and fluorine inventories in the stratosphere based on ATMOS observations at $30^{\circ}$ north latitude," J. Atmos. Chem. 15, 171-186 (1992).

33. R. Zander, E. Mahieu, M. R. Gunson, M. C. Abrams, A. Y. Chang, M. Abbas, C. Aellig, A. Engel, A. Goldman, F. W. Irion, N. Kampfer, H. A. Michelsen, M. J. Newchurch, C. P. Rinsland, R. J. Salawitch, G. P. Stiller, and G. C. Toon, "The 1994 northern mid-latitude budget of stratospheric chlorine derived from ATMOS/ATLAS-3 observations," Geophys. Res. Lett. 23, 2357-2360 (1996).

34. World Meteorological Organization (WMO), "Scientific assessment of ozone depletion: 1998," Report 44 (World Meteorological Organization, P.O. Box 2300, Geneva 2, CH 1211, Switzerland, 1999).

35. A. Y. Chang, R. J. Salawitch, H. A. Michelsen, M. R. Gunson, M. C. Abrams, R. Zander, C. P. Rinsland, J. W. Elkins, G. S. Dutton, C. M. Volk, C. R. Webster, R. D. May, D. W. Fahey, R. S. Gao, M. Loewenstein, J. R. Podolske, R. M. Stimpfle, D. W. Kohn, M. H. Proffitt, J. J. Margitan, K. R. Chan, M. M. Abbas, A. Goldman, F. W. Irion, G. L. Manney, M. J. Newchurch, and G. P. Stiller, "A comparison of measurements from ATMOS and instruments aboard the ER-2 aircraft: halogenated gases," Geophys. Res. Lett. 23, 2393-2396 (1996).

36. J. W. Elkins, D. W. Fahey, J. M. Gilligan, G. S. Dutton, T. J. Baring, C. M. Volk, R. E. Dunn, R. C. Myers, S. A. Montzka, P. R. Wamsley, A. H. Hayden, J. H. Butler, T. M. Thompson, T. H. Swanson, E. J. Dlugokencky, P. C. Novelli, D. F. Hurst,
J. M. Lobert, S. J. Ciciora, R. J. McLaughlin, T. L. Thompson, R. H. Winkler, P. J. Fraser, L. P. Steele, and M. P. Lucarelli, "Airborne gas chromatograph for in situ measurements of long-lived species in the upper troposphere and lower stratosphere," Geophys. Res. Lett. 23, 347-350 (1996).

37. M. R. Gunson, M. C. Abrams, L. L. Lowes, E. Mahieu, R. Zander, C. P. Rinsland, M. K. W. Ko, N. D. Sze, and D. K. Weisenstein, "Increase in levels of stratospheric chlorine and fluorine loading between 1985 and 1992," J. Geophys. Res. 95, 2223-2226 (1994).

38. M. M. Abbas, M. R. Gunson, M. J. Newchurch, H. A. Michelsen, R. J. Salawitch, M. Allen, M. C. Abrams, A. Y. Chang, A. Goldman, F. W. Irion, E. J. Moyer, R. Nagaraju, C. P. Rinsland, G. P. Stiller, and R. Zander, "The hydrogen budget of the stratosphere inferred from ATMOS measurements of $\mathrm{H}_{2} \mathrm{O}$ and $\mathrm{CH}_{4}$," Geophys. Res. Lett. 23, 2405-2408 (1996).

39. H. A. Michelsen, G. L. Manney, M. R. Gunson, and R. Zander, "Correlations of stratospheric abundances of $\mathrm{NO}_{y}, \mathrm{O}_{3}, \mathrm{~N}_{2} \mathrm{O}$ and $\mathrm{CH}_{4}$ derived from ATMOS measurements," J. Geophys. Res. 103, 28,347-28,359 (1998).

40. G. L. Manney, H. A. Michelsen, M. L. Santee, M. R. Gunson, F. W. Irion, A. E. Roche, and N. J. Livesey, "Polar vortex dynamics during spring and fall diagnosed using trace gas observations from the Atmospheric Trace Molecule Spectroscopy instrument," J. Geophys. Res. 104, 18,841-18,866 (1999).

41. A. Lambert, R. G. Grainger, C. D. Rodgers, F. W. Taylor, J. L. Mergenthaler, J. B. Kumer, and S. T. Massie, "Global evolution of the Mt Pinatubo volcanic aerosols observed by the infrared limb-sounding instruments CLAES and ISAMS on the Upper Atmosphere Research Satellite," J. Geophys. Res. 102, 1495-1512 (1997).

42. S. T. Massie, T. Deshler, G. E. Thomas, J. L. Mergenthaler, and J. M. Russell, "Evolution of the infrared properties of the Mount Pinatubo aerosol cloud over Laramie, Wyoming," J. Geophys. Res. 101, 23,007-23,019 (1996).

43. P. B. Russell, J. M. Livingston, R. F. Pueschel, J. J. Bauman, J. B. Pollack, S. L. Brooks, P. Hamill, L. W. Thomason, L. L. Stowe, T. Deshler, E. G. Dutton, and R. W. Bergstrom, "Global to microscale evolution of the Pinatubo volcanic aerosol derived from diverse measurements and analyses," J. Geophys. Res. 101, 18,745-18,763 (1996).

44. L. W. Thomason, L. R. Poole, and T. Deshler, "A global climatology of stratospheric aerosol surface area density deduced from Stratospheric Aerosol and Gas Experiment II measurements: 1984-1994," J. Geophys. Res. 102, 8967-8976 (1997).

45. A. Eldering, F. W. Irion, A. Y. Chang, M. R. Gunson, F. P. Mills, and H. M. Steele, "Vertical profiles of aerosol volume from high-spectral-resolution infrared transmission measurements. I. Methodology," Appl. Opt. 40, 3082-3091 (2001). 